Jurnal Widya Sastra Pendidikan Agama Hindu, Vol 4, No. 2, 2022

ISSN: 2656-7466

\title{
PENERAPAN METODE EXPLICIT INSTRUCTION UNTUK MENINGKATKAN AKTIVITAS DAN PRESTASI BELAJAR PENDIDIKAN AGAMA HINDU DAN BUDI PEKERTI \\ Oleh
}

Luh Putu Windaresa

Email:windaresa@gmail.com

I Wayan Suwendra

Email: suwendra99@gmail.com

STKIP Agama Hindu Singaraja, Singaraja, Indonesia

\begin{abstract}
ABSTRAK
Penelitian ini bertujuan untuk mengetahui Penerapan Metode Explicit Instructions dapat meningkatkan aktivitas dan prestasi belajar Pendidikan Agama Hindu dan Budi Pekerti pada siswa kelas X Multimedia SMK TI Bali Global Singaraja. Subyek penelitiannya adalah siswa kelas X Multimedia SMK TI Bali Global Singaraja dengan subyek penelitian berjumlah 14 orang Penelitian ini dilakukan dalam dua siklus dengan teknik pengumpulan data melalui observasi, wawancara, pemberian tes yang diolah menggunakan analisis deskriptif kuantitatif.

Hasil penelitian ini menunjukkan bahwa terdapat kenaikan yang signifikan pada siklus I dan siklus II terkait aktivitas dan prestasi belajar Siswa kelas X Multimedia SMK TI Bali Global Singaraja sebagai berikut : Aktivitas Belajar pada siklus I sebesar $72,8 \%$ meningkat menjadi $81,7 \%$ pada siklus II pada katagori tinggi Untuk prestasi belajar yaitu : pada siklus I diperoleh nilai rata-rata kelas (M) sebesar 73,9\%, daya serap klasikal (DS) 73,7\%, dan ketuntasan belajar klasikal (KB) 64,3\%. Hal ini meningkat pada siklus II, yaitu nilai rata-rata kelas (M) $80 \%$, daya serap klasikal (DS) $80 \%$, dan ketuntasan belajar klasikal (KB) 85,7\%, .

Berdasarkan hasil tersebut direkomendasikan kepada para guru Agama Hindu agar dapat menggunakan metode ini dalam pembelajaran secara baik dan benar dalam rangka peningkatan kualitas proses dengan hasil belajar siswa.
\end{abstract}

Kata Kunci : Explicit Instructions, Aktivitas Belajar dan Prestasi Belajar 
Jurnal Widya Sastra Pendidikan Agama Hindu, Vol 4, No. 2, 2022

ISSN: 2656-7466

\title{
IMPLEMENTASI NILAI-NILAI KARAKTER YANG TERDAPAT PADA GEGURITAN PENERAPAN METODE EXPLICIT INSTRUCTION UNTUK MENINGKATKAN AKTIVITAS DAN PRESTASI BELAJAR PENDIDIKAN AGAMA HINDU DAN BUDI PEKERTI

\author{
Oleh
}

Luh Putu Windaresa

Email: windaresa@gmail.com

I Wayan Suwendra

Email: suwendra99@gmail.com

STKIP Agama Hindu Singaraja, Singaraja, Indonesia

\begin{abstract}
This study aims to determine the application of the method of Explicit Instructions can increase the activity and learning achievement of Hindu Religious Education and Character in class X Multimedia SMK TI Bali Global Singaraja. The research subjects were students of class X Multimedia at SMK TI Bali Global Singaraja with research subjects totaling 14 people. This research was conducted in two cycles with data collection techniques through observation, interviews, giving tests which were processed using quantitative descriptive and qualitative analysis.

The results of this study indicate that there is a significant increase in cycle I and cycle II related to activity and learning achievement of students of class $X$ Multimedia at SMK TI Bali Global Singaraja as follows: Learning Activities in the first cycle of $72.8 \%$ increased to $81.7 \%$ in the first cycle II in the high category For learning achievement, namely: in the first cycle, the average grade (M) was $73.9 \%$, classical absorption (DS) was $73.7 \%$, and classical learning completeness (KB) was $64.3 \%$. This increased in the second cycle, namely the average grade (M) $80 \%$, classical absorption (DS) 80\%, and classical learning completeness (KB) 85.7\%, .

Based on these results, it is recommended for Hindu Religion teachers to be able to use this method in learning properly and correctly in order to improve the quality of the process with student learning outcomes.
\end{abstract}

Keywords: Explicit Instructions, Learning Activities and Learning Achievement 
Jurnal Widya Sastra Pendidikan Agama Hindu, Vol 4, No. 2, 2022

ISSN: 2656-7466

\section{PENDAHULUAN}

Pendidikan memegang peranan yang sangat penting dalam proses peningkatan kualitas sumber daya manusia. Kualitas sumber daya manusia menyangkut kemampuan manusia baik secara individual maupun secara kolektif untuk bertahan hidup di tengah tuntutan kebutuhan dan ancaman persaingan dari individu dan komunitas manusia lainnya. Pendidikan adalah usaha sadar dan terencana untuk mewujudkan suasana belajar dan proses pembelajaran agar siswa secara aktif mengembangkan potensi dirinya untuk memiliki kekuatan spiritual keagamaan, pengendalian diri, kepribadian, kecerdasan, akhlak mulia, serta keterampilan yang diperlukan dirinya, masyarakat, bangsa dan negara. Tujuan Pendidikan Nasioanal sesuai Pasal 3 Undang-Undang (UU) RI Nomor 20 Tahun 2003, adalah "...untuk berkembangnya potensi siswa agar menjadi manusia yang beriman dan bertawa kepada Tuhan Yang Maha Esa, berakhlak mulia, sehat, berilmu cakap, kreatif, mandiri, dan menjadi warga negara yang demokratis serta bertanggung jawab". Berdasarkan tujuan pendidikan nasional maka Pendidikan Agama dan Budi Pekerti sangat memegang peranan yang sangat penting dalam dunia pendidikan. Apalagi di era globalisasi dewasa ini telah mempengaruhi berbagai tatanan kehidupan umat manusia saat ini, termasuk kemajuan di bidang ilmu pengetahun dan teknologi yang menuntut sumber daya manusia yang handal profesional khususnya di bidang pendidikan. Semua negara menempatkan sistem nilai dan etika sebagai landasan utama dalam merancang kurikulum nasionalnya.

Dalam proses pembelajaran Pendidikan Agama Hindu dan Budi Pekerti, aktivitas siswa masih pasif hanya sebagai pendengar saat pendidik yang dalam hal ini sebagai peneliti, mengamati kegiatan siswa hanya datang, duduk, dengar dan catat selesai hanya sebatas hal tersebut. Dalam proses pembelajaran interaksinya berlangsung dalam satu arah saja yaitu guru yang lebih banyak aktivitas ketimbang siswa yang belajar, tentunya hal ini juga akan berpengaruh terhadap prestasi belajar siswa. Sehingga dapat disimpulkan bahwa aktivitas belajar masih rendah. Berdasarkan pengamatan dibuktikan bahwa dari 14 orang siswa , 6 orang atau hanya $42,9 \%$ siswa yang aktif dalam proses pembelajaran sedangkan 8 siswa atau 57,1 \% siswa pasif. Karena aktivitas siswa rendah otomatis mempengaruhi prestasi belajar siswa juga rendah. Terbukti dari hasil pre-test Pendidikan Agama Hindu dan Budi Pekerti yang dilaksanakan diperoleh hasil prestasi belajar sebagai berikut : secara kuantitatif nilai rata-rata kelas diperoleh 70,7, Daya serap adalah 70,7\%, ketuntasan belajar hanya $28,6 \%$ dari Kriteria Ketuntasan Minimal yang diharapkan peneliti yaitu $75 \%$, dengan rata-rata kelas 75 dan Daya serap $75 \%$. Berdasarkan fenomena di atas dapat disimpulkan bahwa aktivitas dan prestasi belajar pendidikan Agama Hindu dan Budi Pekerti pada siswa Kelas X Multimedia SMK TI Bali Global Singaraja rendah tahun ajaran 2020/2021.

Untuk mengatasi permasalahan di atas, sebagai peneliti di Kelas X Multimedia SMK TI Bali Global Singaraja merasa perlu untuk introspeksi diri tentang hal-hal yang menyebabkan rendahnya aktivitas dan prestasi belajar siswa pada Kelas $\mathrm{X}$ Multimedia SMK TI Bali Global Singaraja. Berdasarkan fenomena di atas ada beberapa alternatif pemecahan masalah yang dapat laksanakan antara lain : 1.) Penerapan metode Explicit Instruction, 2.) Penerapan metode Reinforcement 3.) Penerapan metode Demonstration, 4.) Penerapan metode pemberian tugas. Dari alternative pemecahan masalah di atas dipilih alternative No 1, yaitu Penerapan Metode Explicit Instuction untuk meningkatkan akivitas dan prestasi belajar Pendidikan Agama Hindu dan Budi Pekerti pada siswa Kelas X Multimedia SMK TI Bali Global Singaraja 
Jurnal Widya Sastra Pendidikan Agama Hindu, Vol 4, No. 2, 2022

ISSN: 2656-7466

\section{METODE PENELITIAN}

Jenis penelitian ini adalah tindakan kelas (Classroom Action Reseach), dengan 2 siklus. Metode pengumpulan datanya adalah observasi, wawancara dan tes. Wawancara dan observasi untuk mendapatkan data yang bersifat kualitatif tentang proses pembelajaran dengan metode instruksi yang jelas (Explicit Instruction Method), sedangkan metode tes untuk mengetahui aktivitas dan prestasi belajar Pendidikan Agama Hindu dan Budhi Pekerti siswa.

\section{Metode Explicit Instruction}

Metode explicit instruction adalah suatu metode pembelajaran lansung yang khusus dirancang untuk mengembangkan belajar siswa tentang pengetahuan procedural dan pengetahuan deklaratif yang dapat diajarkan dengan pola selangkah demi selangkah. ( Rosenshine \& Steve, 1986:3). Secara garis besar, terdapat lima langkah dalam metode explicit instruction dimana pada metode ini masih berpusat pada guru, antara lain sebagai berikut : Persiapan (Orientasi), Demonstrasi (Presentasi), Pelatihan Terbimbing (Latihan Terstruktur), Umpan balik (Latihan Terbimbing), dan Pelatihan Lanjutan (mandiri )

\section{Aktivitas Belajar}

Aktivitas belajar merupakan suatu kegiatan yang dilakukan untuk perubahan pengetahuan-pengetahuan, nilai-nilai sikap, dan keterampilan pada Siswa sebagai latihan yang dilaksanakan secara sengaja.(Maisuri, dkk,2008).

Aspek yang dinilai untuk aktivitas belajar siswa yaitu : aktivitas visual (Visual Activities), aktivitas verbal (Oral Activities), aktivitas mendengarkan (Listening Activities) dan aktivitas motorik (Motor Activities). Aspek ini dinilai melalui lembar observasi.

\section{Prestasi Belajar}

Poerwanto (1986:2, dalam ridwan,2008: 202), prestasi belajar yaitu hasil yang dicapai oleh Siswa dalam usaha belajar sebagaimana yang dinyatakan dalam raport. Selanjutnya Winkel (1996:162, dalam ridwan,2008:202), dikatakan bahwa prestasi belajar adalah suatu bukti keberhasilan atau kemampuan Siswa dalam melukukan kegiatan belajarnya, sesuai dengan bobot yang dicapainya. Sedangkan menurut S. Nasution ( 1996:17) prestasi belajar adalah kesempurnaan yang dicapai seseorang dalam berpikir, merasa dan berbuat. Prestasi belajar dikatakan sempurna apabila memenuhi tiga aspek yakni : kognitif, afektif dan psikomotorik, sebaliknya dikatakan presatsi kurang memuaskan jika seseorang belum mampu memenuhi target dalam ketiga kriteria tersebut.

Berdasarkan pengertian di atas dapat disimpulkan bahwa Prestasi belajar adalah suatu gambaran dari penguasaan kompetensi dari siswa yang telah ditetapkan pada suatu palajaran Pendidikan Agama Hindu dan Buddhi Pekerti yang dinilai dengan tes.

\section{HASIL PENELITIAN DAN PEMBAHASAN}

Berdasarkan hasil observasi dan wawancara awal dengan guru mata pelajaran Pendidikan Agama Hindu dan Budi Pekerti Kelas X Multimedia SMK TI Bali Global Singaraja ditemukan hanya sebagian kecil siswa yang mau aktif dalam proses pembelajaran di kelas, baik dalam hal mengajukan pertanyaan, menjawab pertanyaan yang dilontarkan oleh guru ataupun merespon jawaban dari temannya. Sehingga dapat disimpulkan bahwa ativitas belajar sisa masih rendah Sedangkan untuk 
prestasi belajar awal digunakan penilaian dengan pre test yang dilaksanakan pada hari Selasa tanggal 4 Agustus 2020 dengan materi tentang pengertian Upaveda, kedudukan upaveda dalam Veda dan ithiasa . Dari hasil prestasi belajar Pre Test, diperoleh hasil sebagai berikut:Rata-rata klasikal diperoleh 70,7, daya serap 70,7\% dan ketuntasan belajar 28,6\%. Sedangkan target penelitian adalah Rata-rata klasikal 75, Daya serap $75 \%$ dan Ketuntasan Belajar (KKM) sebagai target dalam penelitian ini sebesar $75 \%$. Atas dasar data di atas dipandang perlu adanya perbaikan pelaksanaan proses pembelajaran yang menekankan pada perbaikan pendekatan pembelajarn dan perbaikan pada penggunaan metode pembelajaran yang dikemas dalam pembelajaran yang inovatif yang dirancang dalam sistem siklus.

Pelaksanaan penelitian kelas pada siklus I dilaksanakan pada bulan September 2020 pada Siswa Kelas X Multimedia SMK TI Bali Global Singaraja, pada semester I tahun pelajaran 2020/2021 dengan subyek penelitian sebanyak 14 orang Siswa, yang dirancang dengan penerapan metode Explicit Instruction dalam pembelajaran Pendidikan Agama Hindu dan Budi Pekerti dengan target yang diinginkan $75 \%$ Siswa aktif, rata-rata kelas 75 , daya serap $75 \%$ ketuntasan belajar $75 \%$ pada penelitian ini,

.Hasil penelitian menunjukkan bahwa penerapan metode explicit intruction dapat meningkatkan aktivitas dan prestasi belajar Pendidikan Agama Hindu Dan Budi Pekerti pada Siswa Kelas X Multimedia SMK TI Bali Global Singaraja dengan hasil sebagai berikut:. aktivitas belajar diperoleh dari observasi awal hanya 42,9\% dan pada pelaksanaan siklus I meningkat menjadi $72,8 \%$, Untuk mengetahui hasil prestasi belajar pada siklus I maka diadakan evaluasi yaitu pos tes yang dilaksanakan di akhir siklus I, pada hari Selasa tanggal 30 September 2020. Evaluasi hasil belajar yang digunakan metode achievement test dalam bentuk tes ojektif atau pilihan ganda dengan jumlah soal 20 item masing-masing item bobotnya 1 (satu). Materi pokoknya Upaveda yaitu tentang Pelaksanaan tes dilaksanakan sedemikan rupa sesuai dengan materi yang diberikan, agar setiap siswa dapat bekerja dengan baik dan waktu yang disediakan selama 45 menit. Hasil yang diperoleh dianalisis untuk mendapatkan : Rata-rata kelas( M ), Daya serap( DS ), dan Ketuntasan belajar(KB), sebagai berikut rata-rata kelas (M ) 73,9, daya serap 73,9\% dan Keteuntasan belajar(KB) sebesar 64,3\%. Jika dibandingkan dengan target penelitian yang direncanakan yaitu : nilai rata-rata klasikal (M) 75 , daya serap(DS) $75 \%$ dan ketuntasan belajar(KB) adalah $75 \%$, maka hasil penelitian pada siklus I ini belum mencapai target yang diharapkan. Oleh karena itu perlu perbaikan pada siklus II.

Pelaksanaan siklus II tidak beda jauh dengan siklus sebelumnya, yaitu siklus I. Hanya saja ada beberapa hal pada siklus II yang perlu mendapat perhatian dan penekanan yang lebih khusus selama proses pembelajaran yaitu pada pemahaman konsep untuk memahami materi ajar dan memberikan kesempatan Siswa untuk lebih aktif dalam mengaktualisasikan diri dalam pembelajaran. Pembelajaran diarahkan untuk tercapainya peningkatan proses dan prestasi belajar Siswa. Dalam siklus II ini, penguatan-penguatan terhadap Siswa lebih banyak dan lebih banyak melibatkan Siswa secara langsung dalam proses pembelajaran sehingga aktivitas belajar Siswa lebih meningkat, yang tentunya akan dapat meningkatkan prestasi belajar Siswa. Dalam kegiatan ini, peneliti melaksanakan rencana pembelajaran yang telah disiapkan sebelumnya. Pelaksanaan tindakan dalam siklus II ini juga dilakukan dengan satu kali tatap muka dengan 2 jam pelajaran $2 \times 45$ menit (90 menit) per minggu dan setiap akhir siklus diadakan evaluasi hasil berupa post test dan evaluasi proses menggunakan metode observasi. Untuk siklus II dilaksanakan pada hari Selasa pada bulan Oktober 2020 sampai dengan Selasa 
pada bulan Desember 2020. Dalam pembelajaran di kelas dengan menggunakan penerapan metode Explicit Instruction dalam pembelajaran Pendidikan Agama Hindu dan Budi Pekerti.. Rata-rata aktivitas siswa dalam pembelajaran siklus II sebesar $81.2 \%$.. Berdasarkan data tentang aktivitas belajar siswa pada siklus II dapat dinyatakan bahwa aktivitas siswa tinggi bahkan melampaui dari target yang di harapkan yaitu $75 \%$. Sedangkan untuk mengetahui keberhasilan prestasi belajar pada pelaksanaan siklus II diperlukan adanya evaluasi. Evaluasi terhadap proses pembelajaran yang telah dilaksanakan dinamai post test . Yang terdiri dari evaluasi hasil dan evaluasi proses yang pelaksanaannya di akhir siklus II, tepatnya pada hari Selasa , tanggal 23 Oktober 2020. Evaluasi hasil digunakan tes hasil belajar ( achievement test) dalam bentuk tes ojektif atau pilihan ganda dengan jumlah soal 20 item masing-masing item bobotnya 1 (satu). Materi pokoknya Upaveda tentang Ayur veda dan gandarwaveda. Hasil yang diperoleh tentang prestasi belajar Siswa kelas $X$ melalui post test pada siklus II sebagai berikut : rata-rata kelas(M) menjadi 80 daya serap(DS) meningkat menjadi $80 \%$ dan ketuntasan belajar(KB) meningkat menjadi $85,7 \%$. Sedangkan target yang diinginkan dalam penelitian ini adalah rata-rata kelas(M) 75, daya serap(DS) 75\% dan ketuntasan belajar(KB) sebesar $75 \%$.

Oleh sebab itu, maka tahapan penelitian ini dihentikan sampai siklus II. Tindakan ini dilakukan karena beberapa alasan : 1. Sudah tercapainya target penelitian yang direncanakan, 2 . Terbatasnya waktu yang tersedia dalam penelitian, 3. Hasil yang diperoleh telah menunjukan tingkat kepuasan ( satified) baik proses pembelajaran maupun hasil belajar yang dicapainya. Kenyataan ini menunjukan bahwa hasil penelitian ini telah melampaui target yang diinginkan. Hal ini disebabkan oleh : 1). Penerapan metode explicit instruction dilaksanakan dengan efektif, 2). Suasana pembelajaran yang kondusif, 3). Pembelajaran berorientasi pada Siswa ( student oriented ), dan 4). Adanya bimbingan belajar Siswa. Hasil penelitian menunjukkan bahwa penerapan metode explicit instruction dapat meningkatkan prestasi belajar Siswa dalam Pendidikan Agama Hindu dan Budi Pekerti pada Siswa Kelas X Multimedia SMK TI Bali Global Singaraja . Hal ini ditunjukkan dengan peningkatan aktivitas belajar pada siklus I, 72,8\% meningkat pada siklus II menjadi $81,7 \%$,sedangkan untuk prestasi belajar terjadi peningkatan sebagai berikut : pada siklus I rata-rata kelas ( $M$ ) sebesar 73,9 , daya serap ( DS ) sebesar $73,9 \%$, dan ketuntasan belajar ( KB ) yaitu 64,3\% meningkat pada siklus II sebagai berikut : ratarata kelas ( M ) menjadi $80 \%$ daya serap (DS) menjadi sebesar $80 \%$ dan ketuntasan belajar (KB) menjadi 85,7 \%. Keberhasilan penelitian di atas dipengaruhi oleh terciptanya suatu proses pembelajaran yang kondusif, dimana Siswa merasa senang dan gembira dalam mengikuti pembelajaran, merasa dihargai, bebas dari rasa takut, sehingga memotivasi Siswa untuk lebih aktif dalam pembelajaran, tugas dan latihanlatihan yang diberikan secara langsung dapat dikerjakan dengan senang hati. Semua hal tersebut di atas disebabkan oleh karena penerapan metode explicit instruction dirancang secara khusus tahapan demi tahapan, pengetahuan dan keterampilan yang diberikan melibatkan Siswa secara langsung yang sangat menarik minat Siswa untuk belajar, sehingga dapat meningkatkan aktivitas belajar Siswa dalam pembelajaran dan berimplikasi terhadap meningkatnya prestasi belajar Siswa dalam hal ini adalah Pendidikan Agama Hindu dan Budi Pekerti .

\section{Simpulan}

Berdasarkan hasil penelitian tindakan kelas dengan penerapan metode explicit instruction untuk meningkatkan Aktivitas dan Prestasi belajar Pendidikan Agama 
Jurnal Widya Sastra Pendidikan Agama Hindu, Vol 4, No. 2, 2022

ISSN: 2656-7466

Hindu dan Budi Pekerti siswa kelas X Multimedia SMK TI Bali Global Singaraja maka dapat disimpulkan sebagai berikut:

1. Penerapan metode explicit instruction dapat meningkatkan akitvitas belajar Pendidikan Agama Hindu dan Budi Pekerti pada siswa Kelas X Multimedia SMK TI Bali Global Singaraja tahun pelajaran 2020/2021. Hal ini terbukti pada silkus I rata-rata Aktivitas belajar siswa hanya $72,8 \%$ dan pada siklus II meningkat menjadi $81,7 \%$ pada katagori tinggi. Jadi Aktivitas belajar siswa mengalami peningkatan sebesar $8,9 \%$.

2. Penerapan metode explicit instruction dapat meningkatkan prestasi belajar Pendidikan Agama Hindu dan Budi Pekerti pada siswa Kelas X Multimedia SMK TI Bali Global Singaraja tahun pelajaran 2020/2021. Hal ini terbukti pada siklus I diperoleh nilai rata-rata kelas (M) sebesar 73,9\% ,daya serap klasikal (DS) 73,9\%, dan ketuntasan belajar klasikal (KB) 64,3\%. Hal ini meningkat pada siklus II, yaitu nilai rata-rata kelas (M) $80 \%$, daya serap klasikal (DS) $80 \%$, dan ketuntasan belajar klasikal (KB) $85,7 \%$. Jadi hasil presatasi belajar siswa sudah mengalami peningkatan sebagai berikut. Rata-rata (M) meningkat sebesar $6,1 \%$, daya serap siswa (DS) meningkat sebesar $6,1 \%$, dan ketuntasan belajar (KB) 21,4\%.

\section{DAFTAR PUSTAKA}

Depdiknas, 2003. Undang-Undang Republik Indonesia Nomor 20 Tahun 2003 tentang Sistim Pendidikan Nasional, Jakarta: Depdiknas.

Depdiknas, 2005. Peraturan Pemerintah Republik Indonesia Nomor 19 Tahun 2005 tentang Standar Nasional Pendidikan, Jakarta: Mendiknas.

Depdiknas, 2006. Pedoman Pelaksanaan Penelitian Tindakan Kelas, Jakarta: Dit Prodik Dirjen PMPTK.

Maisuri, Dkk. (2008). http://fikrinatuna. blogspot.com. diakses tanggal 19 Desember 2020.

Nasution S. 1996. . (1996;17). Prestasi Belajar. Jakarta: Penerbit Rineka Cipta

Purwanto. 2009. Evaluasi Hasil Belajar. Yogyakarta: Pustaka Pelajar

Ridwan. 2008. Belajar, Minat, Motivasi,Prestasi Belajar. http://www.artikel. Com/202/Belajar.minat, motivasi, prestasi belajar.

Rosenshine, B., \& Stevens, R. 1986. Teaching functions. In M. C. Wittrock (Ed.), Handbook of research on teaching, 3rd ed. (pp. 376-391). New York: Macmillan. Persada.

Suryabrata, Sumadi. 2010. Metodologi Penelitian. Jakarta: PT RajaGrafindo

Winkel. 1996 Psikologi Pendidikan dan Evaluasi Belajar. Jakarta: Gramedia. Sardiman AM. 1990. Interaksi dan Motivasi Belajar Mengajar. Jakarta: CV.Rajawali. 